\title{
LEARNER VARIABLES AS PREDICTORS OF ESL PROFICIENCY
}

\section{Carisma Dreyer and Johann L. van der Walt}

The fact that some individuals are more successful at acquiring English as an L2 than others has led to investigations of learner characteristics as predictors of ESL proficiency. This paper reports the results of an investigation of the relationship between three learner characteristics, namely Field Independence/Dependence (FI/D), Language Learning Strategies (LLSs) and Personality Types/Traits (PT), and ESL proficiency. Pearson product-moment correlations and canonical correlations revealed significant relationships between $F I / D, L L S s$ and $E S L$ proficiency. A stepwise multiple regression analysis revealed that LLSs accounted for approximately $45 \%$ of the total variance on the TOEFL test.

Die feit dat sommige individue meer suksesvol is as ander in die aanleer van Engels as 'n tweede taal het gelei tot ondersoeke van leerderkenmerke as voorspellers van suksesvolle Engels tweedetaalvaardigheid. Hierdie artikel rapporteer die resultate van 'n ondersoek na die verwantskap tussen drie leerderkenmerke, naamlik veld onafhanklikheid/afhanklikheid (VO/A), taalleerstrategieë (TLS), persoonlikheidstipes/-trekke (PT) en Engels tweedetaalvaardigheid. Pearson produk-momentkorrelasies en kanoniese korrelasies het beduidende verwantskappe tussen VO/A, TLS en Engels tweedetaalvaardigheid aangetoon. 'n Stapsgewyse meervoudige regressie het aangetoon dat taalleerstrategieë verantwoordelik was vir ongeveer $45 \%$ van die totale variansie in die TOEFL toets.

\section{Introduction}

Since the early seventies research concerns in the field of second language learning and teaching have shifted from the methods of teaching to learner characteristics and their possible influence on the process of acquiring a second language. Chapelle and Roberts (1986:28) contend that more research is needed before statements can be made about which combination of learner variables is ultimately crucial to second language (L2) acquisition in a particular setting. Educational research has identified a number of variables that account for some of the differences in how students learn (e.g. attitude, motivation, aptitude, learning styles, learning strategies and personality traits). It is difficult to take all these learner variables into account when investigating their influence on ESL proficiency. The scope of this paper is, therefore, limited to the investigation of three major variables, viz. Field Independence/Dependence (FI/D), Language Learning Strategies (LLSs) and Personality Types/Traits (PT).

The purpose of this article is to identify those variables which might predict the English Second Language (ESL) proficiency of learners of English as a second language. The study is aimed in particular at investigating some variables which might be related to the ESL proficiency of first-year Afrikaans-speaking university students studying English as a second language at the Potchefstroom University.

\section{Field independence/dependence, language learning strategies, personality types/traits and ESL proficiency}

One of the major conundrums in the SLA field is the question of differential success among language learners. Teachers and researchers have all observed that some students are more "successful" (i.e. more proficient) than others in learning a second language. Some individuals appear to be endowed with abilities to succeed; others lack those abilities. This 
observation has led researchers (e.g. Rubin, 1975; Stern, 1975; O'Malley \& Chamot, 1990; Oxford, 1990; Vann \& Abraham, 1990) to describe "good" and "bad" language learners in terms of learning styles, personal characteristics and language learning strategies.

A review of the literature indicates that variables such as attitude, aptitude and motivation have been extensively studied and documented with fairly consistent results, whereas research investigating FI/D, LLSs and PT offers mixed and somewhat inconsistent conclusions. For example, Hansen and Stansfield (1981:365) found positive linear correlations ranging from $r=0,20$ to $r=0,43, p<0,001$ between student's $F I / D$ and performance on various measures of Spanish proficiency. It is clear that these correlations are rather modest. However, Chapelle and Roberts (1986:37) found correlations of $r=0,55$ and $r=0,75, p<0,001$ between FI and TOEFL scores administered at the beginning and end of the semester, respectively. These correlations are significantly higher than those found by Hansen and Stansfield (1981:365), indicating a stronger relationship between field independence and proficiency. The findings of Bialystok and Fröhlich (1978:327-336), on the other hand, attributed a very minor role in second language learning to field independence.

O'Malley et al. (1985a:43) state that the findings from their study suggest that the extension of recent research on language learning strategies in Second Language Acquisition (SLA) is warranted. Language learning strategy research, for all its promise is, as Skehan (1989:98) points out, still "embryonic", with conflicting methods and results and few unequivocal findings. Oxford et al. (1988:327) contend that it would be useful to replicate studies in similar kinds of settings (e.g. replicate a university study at another university) using the same research methods to see if the findings are the same.

According to Reiss (1985:511), personality variables are undoubtedly the most "elusive" of all the learner variables that have been studied. Brodkey and Shore (1976:153-162) have found student personality to be a strong predictor of good and poor language learning behaviour. Skehan (1989:100-118), on the other hand, concludes that personality plays a far more minor role than LLSs. This view is supported by the findings in a study by Busch which was unable to sustain the hypothesis that extroverted students would be more proficient than introverted students. However, according to Brown (1987:110), Busch's study was done in one culture with one group of learners, therefore much more research is needed before conclusions can be drawn.

It is clear, therefore, that the FI/D, LLSs and PT of students require further investigation in order to determine if there is any relation between these variables and ESL proficiency.

The following questions need to be addressed with regard to Afrikaans ESL learners:

* Is there a statistically significant relationship between FI/D and ESL proficiency?

* Is there a statistically significant relationship between LLSs and ESL proficiency?

* Is there a statistically significant relationship between PT and ESL proficiency?

Which independent variable(s) seems to be the most significant predictor(s) of ESL proficiency?

\section{Method of research}

\subsection{Subjects}

The subjects of this study were all Afrikaans (native language) first year students at the Potchefstroom University taking English as a second language. All the first year students taking ENG 111 (81 students) and ENG 112 (224 students) were included in the study. 
ENG 111 refers to the more conventional academic English course, whereas ENG 112 refers to the more practical English course taken mostly by law students. A total number of 305 students (179 females and 126 males), ranging in age from 18 to 21 years, completed all the tests. The differences between the ENG 111 and the ENG 112 course mean that the subjects did not represent a homogeneous group. It was, therefore, aiso possible to compare the two groups.

\subsection{Variables}

The independent (predictor) variables are: Field Independence/Dependence (FI/D) Language Learning Strategies (LLSs), and Personality Types/Traits (PT).

The dependent (criterion) variable in this study is English Second Language (ESL) proficiency.

\subsection{Instrumentation}

Five paper-and-pencil testing instruments were used in this study:

(1) The Gottschaldt Figures Test (GFT) for determining field independence/dependence,

(2) The Strategy Inventory for Language Learning (SILL), a self-report survey of preferred language learning strategies,

(3) The Jung Personality Questionnaire (JPQ) for personality type,

(4) The High School Personality Questionnaire (HSPQ) for a variety of personality traits. and

(5) The Test of English as a Foreign Language (TOEFL) for determining English Second Language (ESL) proficiency.

Each instrument can briefly be described as follows:

The Gottschaldt Figures Test is a test of analytical ability in which the student is required to find embedded figures in more complex diagrams. The student's ability to find the simple figures without becoming distracted by the complex figure indicates the extent to which he/she is field independent.

The SILL is a Likert-scaled, self-report instrument which assesses the frequency with which a respondent uses a variety of different strategies for learning a second language. A typica SILL item asks the respondent to indicate the frequency of use (almost always to almos never, on a five-point scale) of a given strategy. The SILL is divided into six parts. Each par represents a group of strategies:

Part A Remembering more effectively (Memory strategies)

Part B Using all mental processes (Cognitive strategies)

Part $\mathrm{C}$ Compensating for missing knowledge (Compensation strategies)

Part D Organizing and evaluating learning (Metacognitive strategies)

Part E Managing emotions (Affective strategies)

Part F Learning with others (Social strategies) 
The JPQ was constructed in order to give a delineation of an individual's personality structure in terms of Jung's theory of personality. Jung's personality typology entails his concepts of the attitudes of extroversion and introversion and the psychological functions of thinking, feeling, sensing and intuiting.

The HSPQ includes all the more adequately research-demonstrated dimensions of personality from the general personality sphere. It aims at giving the maximum information about the greatest number of dimensions of personality in the shortest time. The test measures fourteen factorially independent personality dimensions.

The TOEFL test is an internationally administered, standardized, multiple-choice test. The purpose of the TOEFL test is to determine the English proficiency of people whose native language is not English. TOEFL contains 150 multiple-choice questions and requires 105 minutes of testing time. The test consists of three sections that are separately timed: Listening comprehension, Structure and Written expression, and Vocabulary and Reading comprehension.

\subsection{Data collection procedure}

The tests for the predictor variables were group-administered during scheduled afternoon tutorial periods at the beginning of April 1991. The "predictor tests" were administered in the following order: GFT, HSPQ, SILL, and the JPQ. The subjects received uniform instructions on how to fill out the various tests. All the requirements stipulated by the various institutions and persons (ETS, HSRC, Prof. R.L. Oxford) regarding the testing atmosphere, instructions, materials, et cetera were adhered to during the test administration. The criterion test, the TOEFL, was group-administered towards the end of June 1991.

\subsection{Design and analysis}

Correlational and multivariate research designs were used in this study. The data were analysed by means of SAS statistical programmes (SAS Institute Inc, 1988).

Pearson product-moment correlations were used to determine the direction and strength of the relationship between the predictor (independent) variables and the criterion (dependent) variables. Canonical correlations were used to determine the relationship between the independent variables and the different sections of the TOEFL test which functioned as the dependent variables (De Wet et al., 1981:188-192; Brown, 1988:96-98; Seliger \& Shohamy, 1989:218-222).

Stepwise multiple regression analyses were also conducted to determine the most significant predictors of the criterion measure. A stepwise multiple regression analysis was conducted separately on each of the independent variables (those that allowed it), namely SILL, JPQ and the HSPQ, using the TOEFL score as the dependent variable. Finally, a stepwise multiple regression analysis was conducted using all the predictor variables and the TOEFL score as the criterion measure (De Wet et al., 1981:240; Seliger \& Shohamy, 1989:222-226).

\subsection{Discussion of results}

In order to ensure a logical order of discussion, the data are discussed under the following headings: proficiency level, field independence/dependence, language learning strategies and personality types/traits. 


\subsubsection{Proficiency level}

In order to make a comparison between the ENG 111 and ENG 112 students it is necessary to determine the proficiency levels of each group. Table 1 gives an indication of the number as well as the percentage of students who obtained A-F symbols in Standard 10.

Table 1:

Symbols obtained for English in Std 10 by ENG 111 and ENG 112 students in Std. 10

\begin{tabular}{|c|c|c|c|c|c|c|}
\hline GROUP & \multicolumn{7}{|c|}{ SYMBOLS } \\
\hline & A & B & C & D & E & F \\
\hline $\begin{array}{c}\text { ENG 111 } \\
(\mathrm{N}=81)\end{array}$ & $\begin{array}{c}21 \\
(25,92 \%)\end{array}$ & $\begin{array}{c}33 \\
(40,74 \%)\end{array}$ & $\begin{array}{c}27 \\
(33,33 \%)\end{array}$ & - & - & - \\
\hline $\begin{array}{c}\text { ENG 112 } \\
(N=224)\end{array}$ & $\begin{array}{c}11 \\
(4,91 \%)\end{array}$ & $\begin{array}{c}32 \\
(14,28 \%)\end{array}$ & $\begin{array}{c}91 \\
(40,62 \%)\end{array}$ & $\begin{array}{c}70 \\
(31,25 \%)\end{array}$ & $\begin{array}{c}18 \\
(8,03 \%)\end{array}$ & $\begin{array}{c}2 \\
(0,90 \%)\end{array}$ \\
\hline
\end{tabular}

A highly significant relationship ( $r=0,83, p<0,0001$ ) was established between the symbol the students obtained in Standard 10 and their performance on the TOEFL test. It can, therefore, be assumed that those students with $A$ and $B$ symbols performed relatively better on the TOEFL test than those students with $\mathrm{D}, \mathrm{E}$ and $\mathrm{F}$ symbols. Table 1 indicates that $66,66 \%$ of the students in ENG 111 obtained A and B symbols, while no student obtained a symbol lower than C. In the ENG 112 group, however, $19,19 \%$ of the students obtained A and B symbols, while $40,18 \%$ obtained symbols lower than C.

It can, therefore, be assumed that the ENG 111 students are relatively better language learners (i.e. more proficient) than the ENG 112 students.

\subsubsection{Field independence/dependence and ESL proficiency}

Pearson product-moment correlations were calculated to determine the direction and strength of the linear relationship between student FI/D, as measured by the GFT, and performance on the TOEFL test. The results appear in Table 2. The correlations between the GFT scores and the TOEFL scores (total and subparts) were all positive, but very low, though with the large number of students involved they were significant $(p<0,01$ and $p<0,05$ ). This finding is consistent with the extensive literature on relationships between measures of FI/D and scores from various language proficiency tests (cf. Tucker et al., 1976; Hansen \& Stansfield, 1981; Day, 1984; Chapelle \& Roberts, 1986).

One problem inherent in correlational analysis is that statistically significant correlations may be found when the observed association is actually rather weak. In this case, the existence of significant and positive correlations is interpreted as an indication that the cognitive restructuring abilities linked to FI are perhaps being utilized to promote successful performance on the TOEFL test (a higher GFT score indicates a relatively greater degree of FI). A t-test indicated that field independence was related to better performance on the TOEFL test, $p<0,05$ (cf. Table 3). 


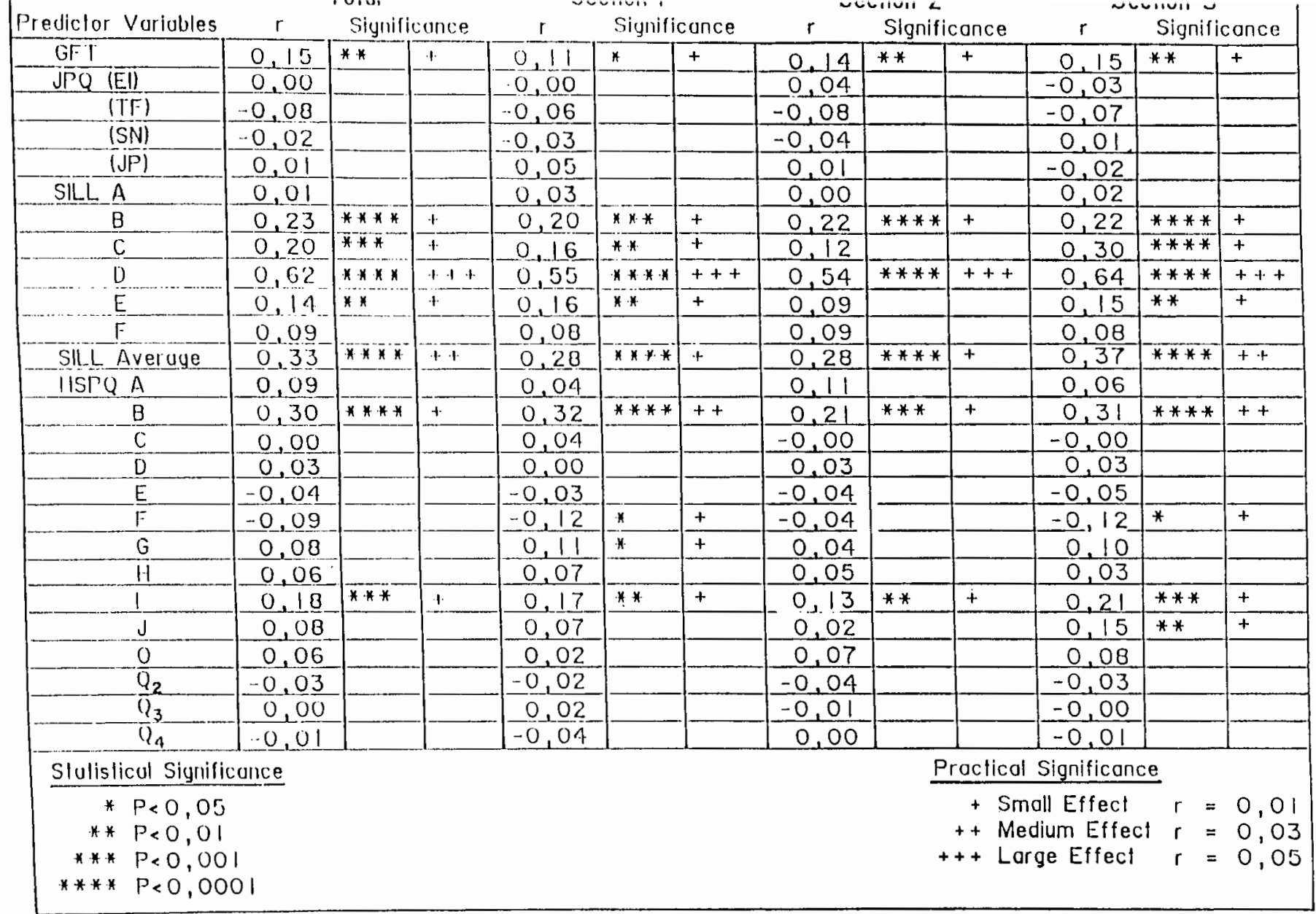


Table 3: Student FI/D and their performance on the TOEFL test

\begin{tabular}{|c|c|c|c|c|c|}
\hline Predictor Variable & N & X & SD & Min & Max \\
\hline GFT $>6(F I)$ & 28 & 519,16 & 36,54 & 480,00 & 596,67 \\
\hline GFT <4 (FD) & 241 & 504,09 & 35,55 & 413,33 & 610,00 \\
\hline
\end{tabular}

In section 3.1 it was mentioned that ENG 111 refers to the conventional academic English course. The content of this course is closely related to "classroom learning" that involves analysis and attention to detail. Students are very often required to display analytical abilities (e.g. in a cloze test). On the other hand, the ENG 112 practical course tends to focus more on natural communication. One of the aims of the course is to improve the communicative competence of the students, in order to equip them for their vocational choices (e.g. law). The results indicated that 19,11\% of the students in the ENG 111 course were relatively field independent, whereas, only $7,46 \%$ of the students in the ENG 112 course were relatively field independent. A t-test revealed that this difference was significant, $\mathrm{p}<0,01$ (cf. Table 4).

Table 4: The number of FI and FD students in ENG 111 and ENG 112

\begin{tabular}{|c|c|c|c|}
\hline Course & N & FI & FD \\
\hline ENG 111 & 68 & $13(19,11 \%)^{*}$ & $55(80,88 \%)$ \\
\hline ENG 112 & 201 & $15(7,46 \%)$ & $186(92,53 \%)$ \\
\hline
\end{tabular}

It seems as if the students in the ENG 111 course have to have a certain degree of FI, whereas the cluster of characteristics associated with FD (cf. Witkin \& Goodenough, 1977; Hansen \& Stansfield, 1981; McLaughlin, 1985) are required in the ENG 112 course. It, therefore, seems plausible to consider the possibility, as does Brown (1987:87), that field independence/dependence is contextualized and variable. Brown (1987:87) states that: "Logically and observationally, field independence/dependence is quite variable within one person". Assuming the "cognitive flexibility" suggested by Brown (1987:88), each individual is capable of using both FI and FD styles to some degree. The style he/she uses depends on the task at hand, as well as the degree to which he/she is able to respond to it appropriately (i.e. be flexible). According to Brown (1987:87-88) it is a misconception to view field independence and field dependence in complementary distribution; some persons might be both highly FI and highly FD as contexts vary. In SLA, then, it may be incorrect to assume that learners should be either field independent or field dependent; it is more likely that persons have general inclinations, but, given certain contexts, can exercise a sufficien 1 degree of an appropriate style.

\subsubsection{Language learning strategies}

Pearson product-moment correlations were calculated to determine the direction anc strength of the relationship between the students' LLS use and their ESL proficiency, as measured by the TOEFL test. The results appear in Table 2. The correlations between the SILL scores and the TOEFL scores were positive and highly significant. This finding is consistent with the literature on the investigation of the relationship between LLS use anc second language proficiency (cf. Bialystok, 1981; O'Malley et al., 1985a; 1985b; Abraham \& Vann, 1987). The strongest correlation $(r=0,64, p<0.0001)$ was obtained between SILL (D) ("organizing and evaluating your learning" - metacognitive strategies) (cf. Oxford, 1990) anc the vocabulary and reading comprehension section (section 3) of the TOEFL test However, the correlations between SILL (D) and the total TOEFL score, as well as the other sub-sections of the TOEFL test, were all strong and highly significant (cf. Table 2) 
The next strongest relationship ( $r=0,23, p<0,0001)$ was found between SILL (B) ("using your mental processes" - cognitive strategies) (cf. Oxford, 1990) and the TOEFL test.

In addition to the Pearson product-moment correlations, canonical correlations were also computed to assess the relationship between LLS use and ESL proficiency. A highly significant correlation of $r=0,73(p<0,0001)$ was found.

Table 5 shows a significant $(\mathrm{p}<0,0001)$ difference in LLS use between ENG 111 and ENG 112 students. This was assessed by means of a $t$-test. It, therefore, seems as if the more proficient language learners (ENG 111 students) (cf. section 3.6.1) are better users of LLSs than the less proficient language learners (ENG 112 students).

Table 5: The difference in LLS use between ENG 111 and ENG 112 students

\begin{tabular}{|l|c|c|c|c|c|}
\hline Course & $\mathbf{N}$ & $\mathbf{X}$ & SD & Min & Max \\
\hline ENG 111 & 81 & 3,24 & 0,36 & 2,36 & 3,88 \\
\hline ENG 112 & 224 & 2,88 & 0,42 & 1,80 & 4,18 \\
\hline
\end{tabular}

$\mathrm{p}<0,0001$

$\mathrm{d}=0,87$

Table 6 shows the frequency of strategy use by ENG 111 and ENG 112 students. The ENG 111 students used the following strategies far more frequently than the ENG 112 students (high category): "Using mental processes" (56,79\% vs $29,91 \%$ ), "compensating for missing knowledge" (29,63\% vs $21,43 \%)$, and "organizing and evaluating learning" $(85,19 \%$ vs $19,64 \%$ ). These figures were obtained by adding the percentages (e.g. $82,72+2,47=$ $85,19 \%$ ) in the two respective high categories (cf. Table 6). In brief, these findings indicate that the ENG 111 students frequently reported employing strategies likely to be useful in a traditional structure-oriented English second language instructional environment geared toward tests and assignments (i.e. academic study requiring analytical abilities). With regard to communicative involvement the ENG 112 students used the social strategies ("learning with others") (high category) more frequently $(45,68 \%$ ) than the ENG 111 students $(26,34 \%)$. This might be as a result of the greater emphasis that is placed on communicative competence in the ENG 112 course. Figure 1 shows a profile of LLS use by the ENG 111 and ENG 112 students. The mean scores in this profile indicate that the ENG 111 students used all of the strategies more often than did the ENG 112 students.

In order to assess the importance of the language learning strategy variable in view of other factors such as the students' FI/D and their personality characteristics, a stepwise multiple regression analysis was done. A summary of the results is shown in Table 7. Language learning strategies accounted for approximately $45 \%$ of the total variance on the TOEFL test. The strategy group "organizing and evaluating your learning" (SILL D) accounted for $41 \%$ of the total variance. As a result SILL D had a significant effect on ESL proficiency $F=(1 ; 303)=211,80, p<0,0001$. The only other variables which showed any effect on ESL proficiency were two personality characteristics (HSPQ B and JPQ SN) (cf. du Toit, 1983; HSRC, 1981), but the effect they had was negligible, because together they accounted for less than $1 \%$ of the total variance on the TOEFL test. In this study, the results seem to indicate that LLSs are the most significant predictors of ESL proficiency, especially strategies in the following groups: "organizing and evaluating your learning" and "managing your emotions". 
TABLE 6: THE FREQUENCY OF STRATEGY USE IBY ENG III AND ENG 112 STUDENTS

\begin{tabular}{|c|c|c|c|c|c|c|}
\hline \multirow[b]{2}{*}{ Cunrse } & & \multicolumn{2}{|c|}{ LOW } & MEDIUM & \multicolumn{2}{|c|}{ HIGH } \\
\hline & LISSs & $\begin{array}{l}\text { Nerer or } \\
\text { almust } \\
\text { never } \\
\text { used } \\
(1-1,5)\end{array}$ & $\begin{array}{c}\text { Usually } \\
\text { not } \\
\text { used }\end{array}$ & $\begin{array}{c}\text { Sumetimes } \\
\text { used }\end{array}$ & $\begin{array}{c}\text { Usually } \\
\text { used }\end{array}$ & $\begin{array}{c}\text { Always or } \\
\text { almust } \\
\text { always } \\
\text { used } \\
(4,51-5)\end{array}$ \\
\hline \multirow{6}{*}{$\begin{array}{l}\text { ENG } 111 \\
(N=81)\end{array}$} & SILL $\wedge$ & 3,70 & 23,40 & 67,90 & 4,94 & - \\
\hline & 13 & - & 1,23 & 41,98 & 54,32 & 2,47 \\
\hline & $C^{\circ}$ & - & 4,94 & 65,43 & 27,16 & 2,47 \\
\hline & 1) & - & 2,47 & 12,35 & 82,72 & 2,47 \\
\hline & $E$ & 1,79 & 28,13 & 59,38 & 10,27 & 0,45 \\
\hline & $1=$ & 2,23 & 28,13 & 43,30 & 22,77 & 3,57 \\
\hline \multirow{6}{*}{$\begin{array}{l}\text { ENG } 112 \\
(N=224)\end{array}$} & SHLL & 5,36 & 36,61 & 52,23 & 5,80 & - \\
\hline & $B$ & - & 11,01 & 58.48 & 29,46 & 0,45 \\
\hline & $c^{\circ}$ & - & 18,75 & 59,82 & 20,09 & 1,34 \\
\hline & 1) & 2,23 & 50,00 & 28,13 & 16,96 & 2,08 \\
\hline & E & 4,94 & 22,22 & 58,02 & 13,58 & 1,23 \\
\hline & F & 2,47 & 17,28 & 34,57 & 39,51 & 0,17 \\
\hline
\end{tabular}


TABLE 7: MULTIPLE REGRESSION ANALYSIS USING GTT, SILL, JPQ AND IISPQ SCORES AS PREDICTORS OF ESL PROFICIENCY

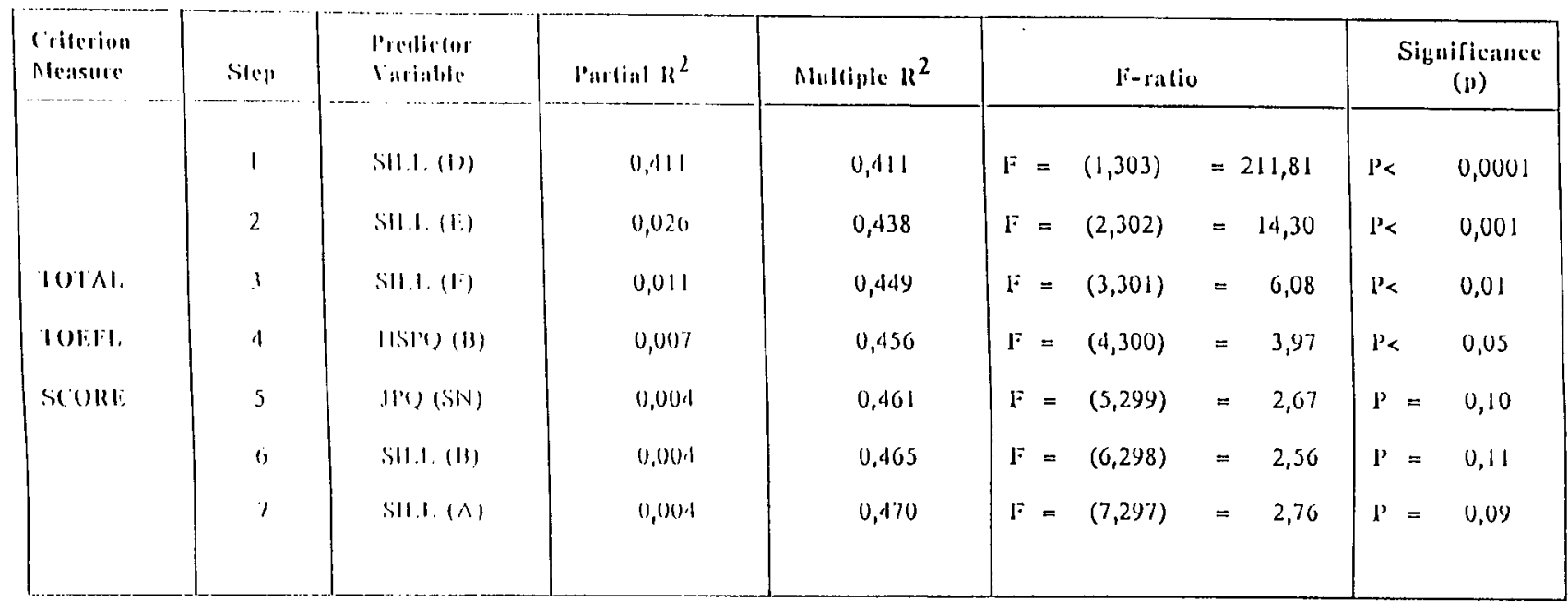




\subsubsection{Personality types/traits}

Pearson product-moment correlations were calculated to determine the direction and strength of the relationship between personality characteristics and ESL proficiency. The results appear in Table 2 . The correlations between the JPQ scores and the TOEFL scores were very low and none of the relationships were significant. The correlations between the HSPQ scores and the TOEFL scores were also low, but slightly better than those for the JPQ. The results indicated that factor B and factor I of the HSPQ (cf. HSRC, 1981) had the strongest and also the most significant relationship $(p<0,0001$ and $p<0,01)$ with ESL proficiency (cf. Table 2).

In addition to the Pearson product-moment correlations, canonical correlations were computed to assess the relationship between personality characteristics and ESL proficiency. A statistically non-significant correlation of $r=0,15$ was found between the JPQ scores and the TOEFL scores, whereas a significant correlation of $r=0,46, p<0,0001$ was found between the HSPQ scores and the TOEFL scores. This implies a common variance of $21 \%$ between the HSPQ scores and the TOEFL scores.

In order to determine the contribution of the HSPQ factors of predicting ESL proficiency, a stepwise multiple regression analysis was done. The results appear in Table 8. From these results it is clear that factors B and I played an important role in the prediction of ESL proficiency, and that five factors of the HSPQ accounted for $13 \%$ of the total variance on ESL proficiency as determined by the TOEFL test.

An explanation for the lack of stronger relationships and more significant results could be that personality characteristics alone are not enough to account for the variance in English proficiency scores. Rather, a combination of certain variables would be more likely to influence a person's success or failure in learning a second language. For this reason the possibility that personality characteristics such as extroversion, assertiveness, adventurousness, and so on, can play important roles in the SLA process, cannot be discounted. According to Larsen-Freeman and Long (1991:186) it is conceivable that cultures value personality characteristics differently and that this might affect the way in which personality characteristics influence SLA. This might provide another explanation of the particular correlations obtained between the various personality characteristics and ESL proficiency.

\section{Conclusion}

Given the phenomenon of differential success among second language learners, researchers have attempted to isolate particular learner characteristics which enhance or hinder progress in learning English as a second language. Although learner variables are not yet well understood, the selective study of some of these variables has shown that there are variables, especially language learning strategies, which can have an important as well as significant influence in predicting ESL proficiency.

With regard to the questions posed in section 2 , the results of this study indicate the following:

* There is a statistically significant relationship $(p<0,05 ; p<0,01)$ between FI/D and ESL proficiency.

* There is a statistically significant relationship (e.g. $r=0,73, p<0,0001$ ) between LLSs and ESL proficiency.

* There is a statistically significant relationship between some of the personality traits (HSPQ (B), $\mathrm{p}<0,0001, \mathrm{HSPQ}(\mathrm{I}), \mathrm{p}<0,001$ ) and ESL proficiency. 
TABLE 8: STEPWISE MULTIPLE REGRESSION ANALYSIS USING IISPQ SCORES AS PREDICTORS OF ESL PROFICIENCY

\begin{tabular}{|c|c|c|c|c|c|c|c|c|}
\hline $\begin{array}{l}\text { Citerion } \\
\text { Neasure }\end{array}$ & Slep & $\begin{array}{l}\text { Proticlur } \\
\text { l'aniablete }\end{array}$ & Piartial $k^{2}$ & Mulliple $\mathrm{R}^{2}$ & \multicolumn{2}{|c|}{ fi-ratio } & \multicolumn{2}{|c|}{$\begin{array}{c}\text { Significance } \\
\text { (1) }\end{array}$} \\
\hline & 1 & IISP() (B) & 0,085 & 0,08 & $1:=(1,303)$ & $=28,45$ & $P_{<}$ & 0,0001 \\
\hline I0IAI. & 2 & IISI (1) & 0,023 & 0,10 & $\mathrm{~F}=(2,302)$ & 8,03 & $P<$ & 0,01 \\
\hline Toliti. & 3 & IISPC) (1:) & 0,007 & 0,11 & $\mathrm{I}^{\mathrm{F}}=(3,301)$ & 2,51 & $\mathrm{P}<$ & 0,11 \\
\hline scouli. & 4 & $\max (\lambda)$ & 0,011 & 0,12 & $F=(4,300)$ & 3,92 & $P<$ & 0,05 \\
\hline & 5 & ISI) & 0,008 & 0,13 & $F=(5,299)$ & $=3,01$ & $P=$ & 0,08 \\
\hline
\end{tabular}


* Overall the results indicate a relative lack of significant relationships between personality characteristics and ESL proficiency.

To what extent a tendency towards either FI or FD affects SLA is difficult to say as the research results are mixed and somewhat inconsistent. In this study the results indicate that field independence is an individual learner characteristic that plays a positive and significant, although minor, role in the development of ESL proficiency. Consequently, the data imply that teachers might be well advised to be aware of the role their students' level of FI/D can play in the English Second Language acquisition process.

Depending upon the context of learning, it seems as if individual learners can vary their utilization of field independence or field dependence. It seems as if "natural" language learning requires, on the other hand, a field dependent style and that classroom learning requires, conversely, a field independent style. It would, therefore, appear as if field independence/dependence might provide one construct, as Brown (1987:87) mentions, which differentiates "classroom" (tutored) second language learning from "natural" (untutored) second language learning.

In this study the "unsuccessful" language learners claim to have used the same strategies as the "successful" language learners, although not with the same frequency (cf. Table 6; Figure 1). These findings call into question the common assumptions in the SLA field, articulated by Wenden (1985:7), that "ineffective learners are inactive learners" and that "their apparent inability to learn is, in fact, due to their not having an appropriate repertoire of learning strategies". However, it is also obvious (cf. Table 6; Figure 1) that successful English Second Language learners frequently, if not always, use effective language learning strategies. Therefore, it seems that English second language learners would gain from being taught these strategies.

The importance of LLSs in predicting ESL proficiency has clear implications for teacher training. Intervention by the teacher could help less able students profit from the strategies used by more able students, and even the more able students could be provided with opportunities to refine and add to their language learning strategies so that they can become as efficient as possible.

Various teacher training models for this purpose have already been developed (cf. Joyce \& Showers, 1987). These teacher training models help orientate teachers to understanding the value of LLSs. First, they are presented with information on LLSs. Teachers are then allowed to experiment with new techniques in the classroom, while receiving feedback from other more experienced teachers.

Although this study has produced significant relationships between some personality traits and ESL proficiency, these findings and the lack of correlation between other personality types/traits and ESL proficiency require further explanation and research. While there is no evidence that certain personality types/traits are either a necessary or a sufficient condition for swift and successful second language learning, there is a possibility that personality types/traits may influence SLA indirectly as opposed to directly.

Different cultures may also value certain personality types/traits differently (cf. section 3.6.4). This has certain implications for the definition of personality types/traits, because researchers will have to define certain personality types/traits cross-culturally, in order to understand how different cultures express feelings, for example, empathy.

Language learning strategies accounted for approximately $45 \%$ of the total variance on the TOEFL test, whereas the contribution of the other variables was much smaller. This seems to indicate that a combination of variables, including FI/D, might play a more significant role in predicting ESL proficiency than only one particular variable. Increasing the language learning strategies which ESL learners use may enhance their proficiency. Whilst the findings in this study cannot be seen as conclusive, they do suggest the usefulness of such lines of enquiry. 


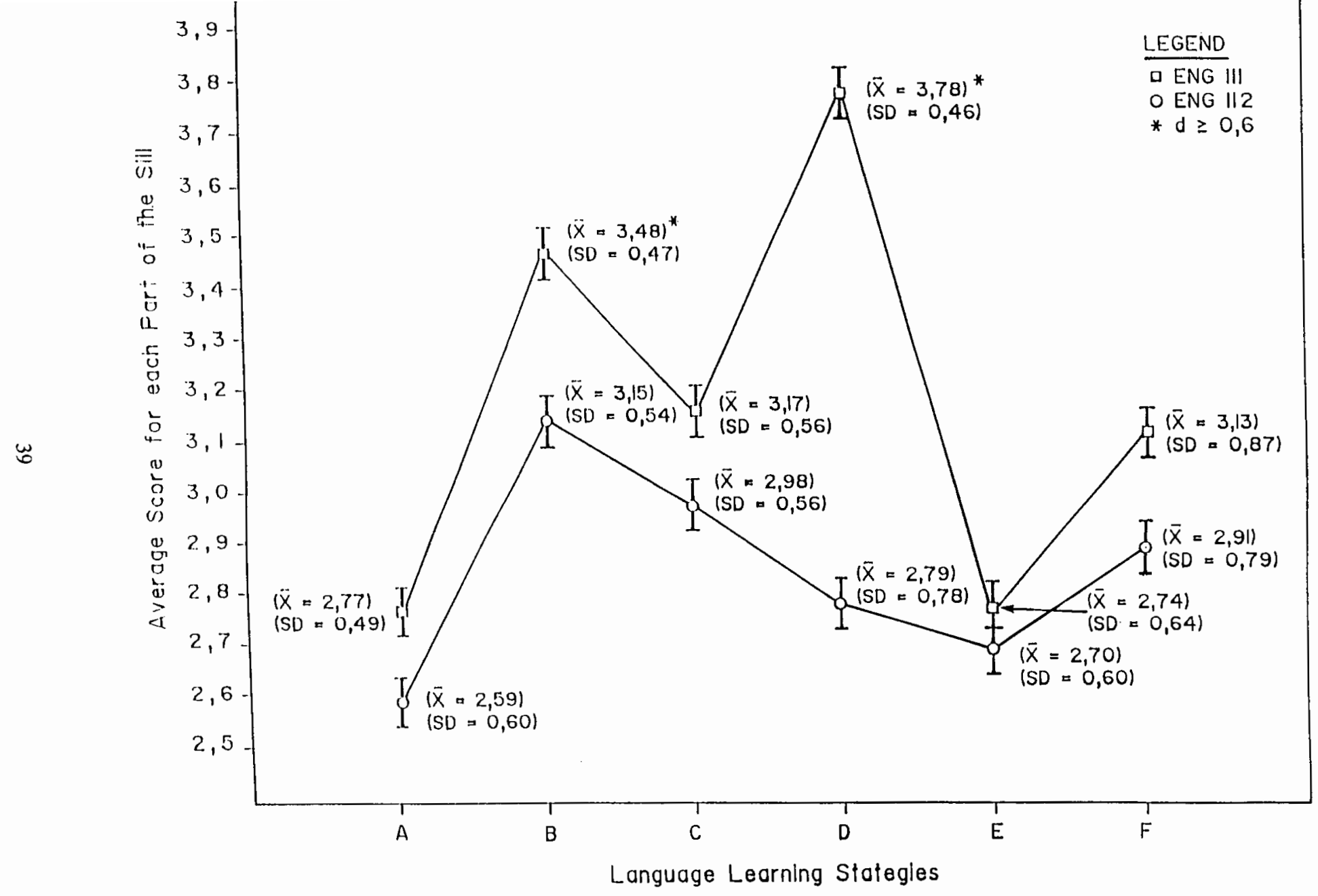




\section{References}

ABRAHAM, RG \& RJ VANN. 1987. Strategies of two language learners: a case study. In WENDEN, A \& J RUBIN (Eds), Learner strategies in language learning. London: Prentice-Hall.

BIALYSTOK, E. 1981. The role of conscious strategies in second language proficiency. The Modern Language Journal, 65(1):24-35.

BIALYSTOK, E \& M FRÖHLICH. 1978. Variables of classroom achievement in second language learning. The Modern Language Journal, 62(7):336-344.

BRODKEY, D \& H SHORE. 1976. Student personality and success in an English language program. Language Learning, 26(1):153-162.

BROWN, HD. 1987. Principles and practices in second language teaching and learning. Rowley, Mass.: Prentice-Hall.

BROWN, JD. 1988. Understanding research in second language learning. New York: Cambridge University Press.

BUSCH, D. 1982. Introversion-extroversion and the ESL proficiency of Japanese students. Language Learning, 32(1):109-132.

CHAPELLE, C \& C ROBERTS. 1986. Field independence and ambiguity tolerance as predictors of proficiency in English as a second language. Language Learning, 36(1):27-46.

DAY, RR. 1984. Student participation in the ESL classroom or some imperfections in practice. Language Learning, 34(3):69-102.

DE WET, JJ, JL De K MONTEITH, HS STEYN \& PA VENTER. 1981. Navorsingsmetodes in die opvoedkunde: ' $n$ inleiding tot empiriese navorsing. Pretoria: Butterworth.

HANSEN, J \& C STANSFIELD. 1981. The relationship of field dependent-independent cognitive styles and foreign language achievement. Language Learning, $31(2): 349-367$.

LARSEN-FREEMAN, D \& MH LONG. 1991. An introduction to second language acquisition research. London: Longman.

McLAUGHLIN, B. 1985. Second language acquisition in children. Vol. 2: School-age children. Hillsdale, NJ: Erlbaum.

O'MALLEY, JM \& AU CHAMOT. 1990. Learning strategies in second language acquisition. Cambridge: Cambridge University Press.

O'MALLEY, JM, AU CHAMOT, G STEWNER-MANZANARES, L KUPPER \& R RUSSO. 1985a. Learning strategies used by beginning and intermediate ESL students. Language Learning, 35(1):21-46.

O'MALLEY, JM, R RUSSO, AU CHAMOT, G STEWNER-MANZANARES \& L KUPPER. 1985b. Learning strategy applications of students of English as a second language. TESOL Quarterly, 19(4):557-584.

OXFORD, RL. 1990. Language learning strategies: what every teacher should know. New York: Harper Collins. 
OXFORD, RL, M NYIKOS \& M EHRMAN. 1988. Vive la difference? Reflections on sex differences in the use of language learning strategies. Foreign Language Annals, 21(4):321-329.

REISS, MA. 1985. The good language learner: another look. The Canadian Modern Language Review, 41(3):511-523.

RUBIN, J. 1975. What the good language learner can teach us. TESOL Quarterly, 9(1):4145.

SAS INSTITUTE INC. 1988. SAS/STAT user's guide. Release 6.03 ed. Cary, NC.: SAS Institute Inc.

SELIGER, HW \& E SHOHAMY. 1989. Second language research methods. Oxford: Oxford University Press.

SKEHAN, P. 1989. Individual differences in second language learning. London: Edward Arnold.

STERN, HH. 1975. What can we learn from the good language learner? The Canadian Modern Language Review, 31(3):304-318.

TUCKER, GR, E HAMAYAN \& F GENESEE. 1976. Affective, cognitive and social factors in second language acquisition. The Canadian Modern Language Review, 32(2):214-226.

VANN, RJ \& RG ABRAHAM. 1990. Strategies of unsuccessful language learners. TESOL Quarterly, 24(2):177-198.

WENDEN, A \& J RUBIN (Eds). 1987. Leamer strategies in language leaming. Englewood Cliffs, NY.: Prentice-Hall.

WITKIN, HA \& DR GOODENOUGH. 1977. Field dependence and interpersonal behaviour. Psychological Bulletin, 84(4):661-689. 